\title{
Review
}

\section{Genetics of sudden cardiac death in the young}

\author{
Saenen J.B., Van Craenenbroeck E.M., Proost D., Marchau F., Van Laer L., \\ Vrints C.J., Loeys B.L. Genetics of sudden cardiac death in the young. \\ Clin Genet 2014. (C) John Wiley \& Sons A/S. Published by John Wiley \& \\ Sons Ltd, 2014
}

Sudden cardiac death (SCD) has an enormous impact on those who are left behind, evoking strong feelings of anxiety and incomprehension because such a dramatic event was not anticipated. Moreover, over the last decade a prominent genetic contribution to the pathogenesis of SCD has been unveiled. As many inherited cardiac diseases show an autosomal dominant pattern of inheritance, the risk of carrying the same inherited predisposition is a real concern for the relatives. In this article, we discuss the major causes of primary electrical disorders, cardiomyopathies and thoracic aortic dissection and address issues in genotype-phenotype correlation, personalized management and cardiogenetic counselling.

\section{Conflict of interest}

The authors declare no conflicts of interest.

\author{
J.B. Saenena , E.M. Van \\ Craenenbroeck $^{a}$, D. Proost ${ }^{b}$, \\ F. Marchauc, L. Van Laer', \\ C.J. Vrints ${ }^{a}$ and B.L. Loeys ${ }^{b}$

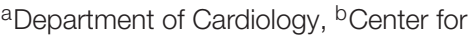 \\ Medical Genetics and , and ${ }^{\mathrm{C}}$ Department \\ of Pediatric Cardiology, Antwerp \\ University Hospital/University of Antwerp, \\ Antwerp, Belgium \\ Key words: cardiogenetics - \\ cardiomyopathy - primary electrical \\ disorder - thoracic aortic aneurysm \\ Corresponding author: Bart Loeys, \\ Center for Medical Genetics, Antwerp \\ University Hospital/University of \\ Antwerp, Prins Boudewijnlaan 43, 2650 \\ Antwerp, Belgium. \\ e-mail: bart.loeys@uantwerp.be
}

Received 23 March 2014, revised and accepted for publication 6 October 2014
Sudden cardiac death (SCD) is a leading cause of mortality with an annual incidence of one death per 1000 person-years, affecting all ages (1). SCD is defined as death that ensues from any cardiac disease within $1 \mathrm{~h}$ after the onset of symptoms (2). The vast majority of SCD in persons older than 45 years $(80 \%)$ are due to advanced atherosclerotic coronary artery disease (CAD) that results in myocardial ischaemia and fatal arrhythmias (3). However, in the young ( $<45$ years), inherited causes of SCD are more frequently observed. The four most common categories in the young include premature atherosclerosis, primary electrical disease (PED), cardiomyopathies (CM) and thoracic aortic aneurysm and dissection (TAAD). The CAREFUL study in the Netherlands showed that inherited cardiac disease was suspected or could not be excluded in almost $80 \%$ of all sudden death victims $(4,5)$.

SCD has an enormous impact on the surviving relatives as they are confronted with the question whether this event could have been prevented. Moreover, the fact that many inherited cardiac diseases, with the associated risk of SCD, segregate in an autosomal dominant way, is a real concern for the relatives. Over the last decade, the care of the patient with a potential cardiogenetic disorder has evolved tremendously. Indeed the paradigm has shifted from the primary cardiac care for the individual proband to an integrated cardiogenetic approach in which both the proband and his family members are investigated. The identification of dozen of genes and the use of advanced molecular techniques allows a molecular diagnosis, identification of high-risk relatives and the preventive treatment or presymptomatic follow-up. These may include lifestyle modifications, pharmacological treatment, implant of a cardiovertor defibrillator or radiofrequency ablation. In Fig. 1, we have depicted on the ideal cardiogenetic workflow of which includes different investigations. In real life and too often, early clues for diagnosis are missed in emergency care (e.g. first-documented rhythm), toxicology reports are lacking, family members are not enquired and autopsy is rarely performed. In such situations, a dedicated evaluation through a cardiogenetics clinic with complementary clinical and genetic testing is extremely beneficial for the family (6). In the case of an unexplained SCD, when autopsy did not reveal the cause of death or was not performed, an inherited cardiac disease could be detected in $22-53 \%$ of families by cardiogenetic screening (7). Yet, incomplete genetic data and unknown prognostic determinants still hamper development of individualized risk stratification models. Despite these shortcomings, cardiogenetic screening of first-degree relatives of SCD probands in tertiary centres 


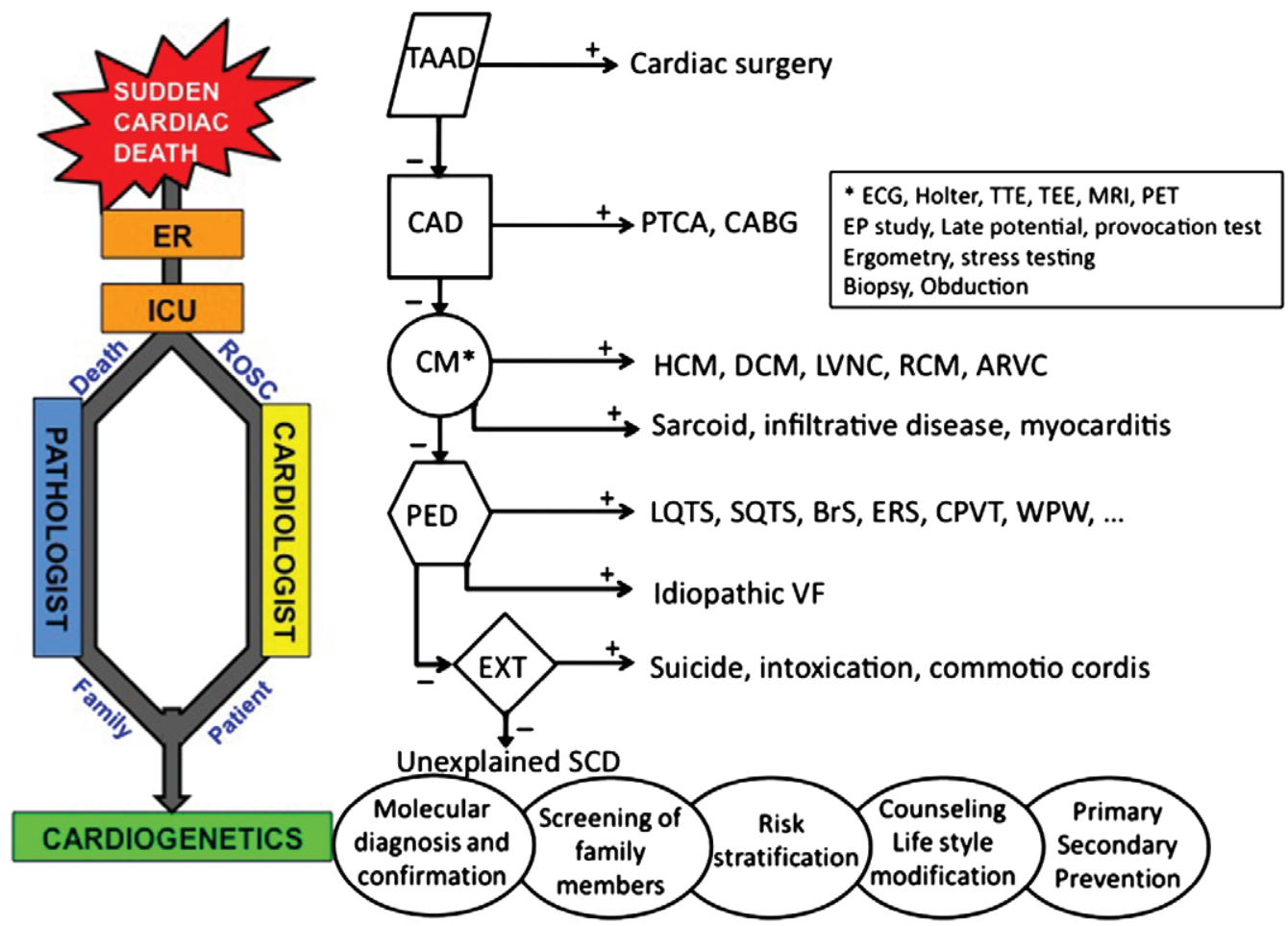

Fig. 1. Cardiogenetic workflow of different investigations. ER, emergency room; ICU, intensive care unit; ROSC, return of spontaneous circulation; TAAD, thoracic aortic aneurysm and dissection; CAD, coronary artery disease; CM, cardiomyopathy; PED, primary electrical disorder; EXT, exterior causes; SCD, sudden cardiac death; ECG, electrocardiogram; TTE, transthoracal echocardiography; TEE, transesophageal echocardiography; MRI, magnetic resonance imaging; PET, positron emission tomography; EP, electrophysiological study; PTCA, percutaneous transluminal coronary angioplasty; CABG, coronary artery bypass graft surgery; HCM, hypertrophic cardiomyopathy; DCM, dilated cardiomyopathy, LVNC, left ventricular non-compaction cardiomyopathy; RCM, restrictive cardiomyopathy; ARVC, arrhythmogenic right ventricular cardiomyopathy; LQTS, long QT syndrome; SQTS, short QT syndrome; BrS, Brugada syndrome, ERS, early repolarization syndrome; CPVT, catecholaminergic polymorphic ventricular tachycardia; WPW, Wolf-Parkinson-White; VF, ventricular fibrillation.

is currently a cost-effective approach in the prevention of SCD (8).

This article gives a concise and comprehensive overview of the fast growing field of inherited cardiac diseases that predispose to SCD. It aims at providing more insight in the complexity of polygenic cardiac disease and to provide evidence of the impact of genetic testing on prevention and treatment of inheritable SCD. In this article, we will cover three main groups: PED, $\mathrm{CM}$ and aortic aneurysm/dissection.

\section{Primary electrical disease}

The vast majority (up to 93\%) of SCD is caused by cardiac arrhythmias such as ventricular tachycardia (VT) and ventricular fibrillation (VF). Although the presence of structural heart disease constitutes a potential arrhythmogenic substrate, life-threatening ventricular arrhythmias in PED arise from electrical derangement without apparent structural cardiac changes.

Mechanistically, PED are caused by molecular defects mostly in ion channels involved in cardiac action potential (AP) generation. In general, PED is caused by a 'gain' or a 'loss of function' of one or more ionic currents that alters the balance between the depolarizing and repolarising forces during the ventricular AP (Fig. 2). This results in a pathologic shortening or prolongation of the AP duration (APD) and leads to an increase of the APD dispersion, a condition that is pro-arrhythmogenic. Both mutations in genes encoding the cardiac ion channels and their accessory proteins have been implicated (Fig. 2; Table S1, Supporting Information).

\section{Long QT syndrome}

The long QT syndrome (LQTS) arises from the pathologic APD prolongation that underlies the proarrhythmogenic transmural dispersion of repolarization. After exclusion of secondary QT prolonging causes, the clinical diagnosis is made in the presence of a LQTS risk score $\geq 3.5$ and/or when the QTc interval is $480-499 \mathrm{~ms}$ on serial 12-lead ECGs in a patient with unexplained syncope, or when a QTc $>500 \mathrm{~ms}$ is found repeatedly in asymptomatic patients (9). This condition predisposes to the initiation and propagation of Torsade de Pointes (TdP), which is usually self-terminating but can degenerate into VF and thus SCD.

The estimated prevalence of LQTS is 1:2500-1:5000 (10). To date, 13 different types of inherited LQTS have been described (Table S1) accounting for $70 \%$ of all LQTS cases. The majority is inherited in an autosomal dominant manner and classified as Romano-Ward syndrome (RWS). A rare variant type-1 LQTS, called the Jervell and Lange-Nielsen syndrome (JLNS), is 
Genetics of SCD

(a)

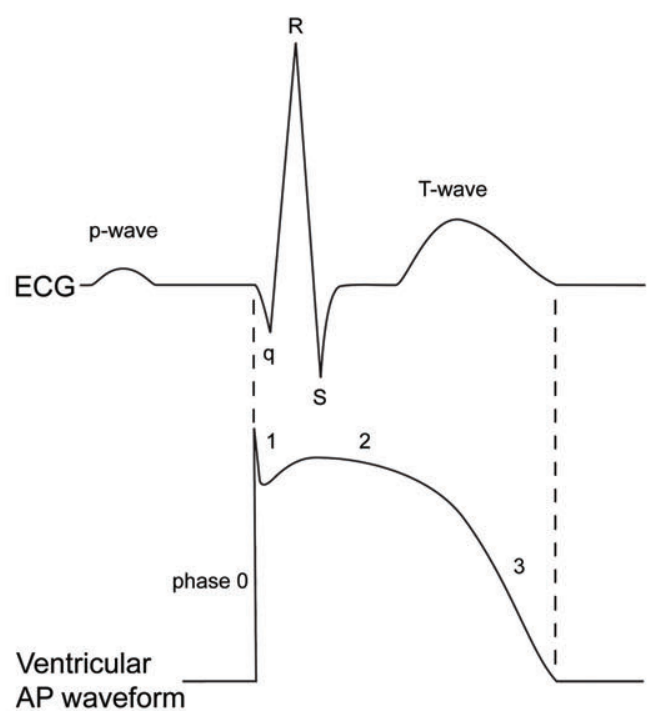

(b)
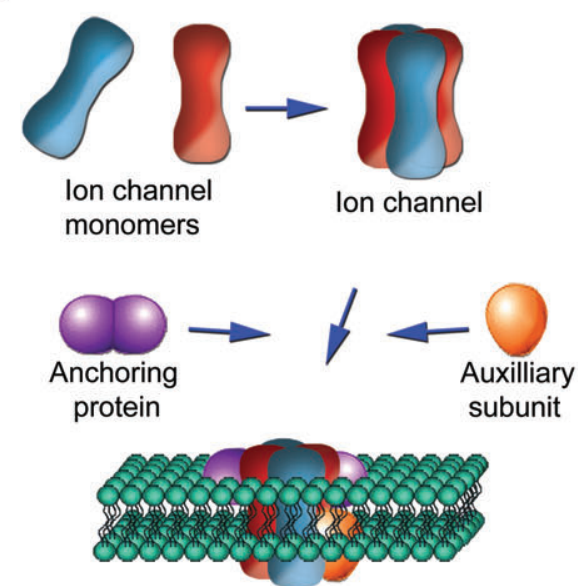

Functional ion channel

(c)

Ion channel Gene

SCN5A

KCND2/KCND3

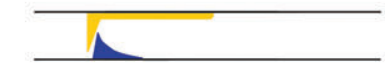

CACNA1C

KCNQ1

$\mathrm{KCNH} 2$

KCNJ2

KCNJ5

KCNJ8

HCN4

\section{Auxilliary Gene}

SCN1B

$S C N 3 B$

$S C N 4 B$

MOG1

SLMAP

TRPM4

GPD1L

SNTA1

CAV3

AKAP9

KCNE1

KCNE2

KCNE3

KCNE5
DPP6

CACNAB2b

CACNA2D1

ANK2

ABCC9

Excitation contraction coupling

RYR2

TRDN

CASQ2

CALM1
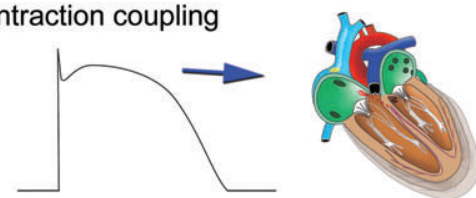

Ionic current

Nav1.5/ /

Kv4.2/Kv4.3/I,

Cav1.2 / L-type I

KvLQT1/ $I_{\text {Ks }}$

hERG / $/ I_{\mathrm{Kr}}$

$\mathrm{Kir} 2.1 / \mathrm{I}_{\mathrm{K} 1}$

Kir3.4 / GIRK4 / I KATP-1

Kir6. $1 / I_{\text {KATP }}$

I,

Auxilliary protein Gain of function

Nav1.5 $\beta 1$-subunit

Nav1.5 $\beta 3$-subunit

Nav1.5 $\beta 4$-subunit

Nav1.5 modulator

Nav1.5 modulator

Nav1.5 modulator

Nav1.5 modulator

Nav1.5 modulator

Nav1.5 modulator

$\mathrm{I}_{\mathrm{K}_{\mathrm{s}}}$ modulator

$\mathrm{K}_{\mathrm{Ks}} \beta$-subunit

${ }_{\mathrm{kr}} \beta$-subunit

$I_{\text {to, } 1} \beta$-subunit

$I_{\text {to }, 1}$ modulator

Cav1.2 $\beta$-subunit

Cav1.2 $\delta$-subunit

Anchoring protein

ATP binding cassette

transporter

Protein

$\mathrm{I}_{\text {CICR }}$ (Electrotonic coupling) CPVT1

$\mathrm{I}_{\text {CICR }}$ Modulator

Calcium buffer

Calcium binding
ERS5

LQTS10

BrS14, PCCD-IB

LQTS12

LQTS9

BrS6

BrS-susceptibility

IVF2

\section{LQTS3 \\ BrS1, ERS6, PCCD-IA, $\mathrm{DCM}+\mathrm{CCD}$, IVF1}

LQTS8

SQTS2

ceptibility,

BrS9, ERS1

Unknown

BrS3, ERS2, SQTS4

LQTS1 (RWS/JLN1)

LQTS2

SUDS

SUDS

LQTS7

LQTS13

$\mathrm{BrS8}$

Unknown

BrS5, CCD

BrS7

BrS12

BrS13

$\mathrm{BrS14}$, isolated CCD(RBBB)

BrS2

SIDS

\section{LQTS11}

LQTS5, JLN2

LQTS6

BrS4, ERS3, SQTS5

BrS10, ERS4, SQTS6

LQTS4 (ankyrin-B syndrome)

DCM

Gain of function Loss of function

Unknown

ARVC2, SUDS

Fig. 2. (a) Relation between the ECG and ventricular AP. (b) Schematic representation of the functional expression of the ion channel complex. Ion channels are represented as heterotetramers corresponding with voltage-gated potassium channels. (c) Overview of the putative pathogenic genes and proteins that underlie PED. SCD, sudden cardiac death; ECG, electrocardiogram; ARVC, arrhythmogenic right ventricular cardiomyopathy; LQTS, long QT syndrome; SQTS, short QT syndrome; BrS, Brugada syndrome; ERS, early repolarisation syndrome; CPVT, catecholaminergic polymorphic ventricular tachycardia; WPW, Wolf-Parkinson-White syndrome; IVF, ideopathic ventricular fibrillation; SUDS, sudden unexplained death syndrome; SIDS, sudden infant death syndrome; DCM, dilated cardiomyopathy; CCD, cardiac conduction disease; RBBB, right bundle branch block; RWS, Romano-Ward syndrome; JLNS, Jervell-Lange-Nielsen syndrome; CICR, calcium-induced calcium release; ATP, adenosine triphosphate; AP, action potential. 
Saenen et al.

Table 1. Overview of main characteristics of different causes of SCD

\begin{tabular}{|c|c|c|c|c|c|c|}
\hline Condition & $\begin{array}{l}\text { Principal pathogenetic } \\
\text { mechanism }\end{array}$ & $\begin{array}{c}\text { Genetic } \\
\text { testing yield }\end{array}$ & Penetrance & $\begin{array}{l}\text { Prognostic } \\
\text { value }\end{array}$ & $\begin{array}{l}\text { Therapeutic } \\
\text { value }\end{array}$ & References \\
\hline Brugada syndrome & $\begin{array}{l}\text { Ion channel } \\
\text { disease/epicardial } \\
\text { RVOT fibrosis: } \\
\text { epicardial AP dome } \\
\text { truncation and/or slow } \\
\text { conduction }\end{array}$ & $20-30 \%$ & $12-50 \%$ & + & - & $(9,93)$ \\
\hline Long QT syndrome & $\begin{array}{l}\text { Ion channel disease: } \\
\text { heterogeneous } \\
\text { transmural APD } \\
\text { prolongation }\end{array}$ & $30-65 \%$ & $40 \%$ & +++ & ++ & (9) \\
\hline Short QT syndrome & $\begin{array}{l}\text { Ion channel disease: } \\
\text { pathogenic APD } \\
\text { shortening }\end{array}$ & $14 \%$ & $100 \%$ & - & - & (9) \\
\hline ERS & $\begin{array}{l}\text { Ion channel disease: } \\
\text { epicardial increase of } \\
\text { AP notch }\end{array}$ & $4-8 \%$ & Low & - & - & (19) \\
\hline CPVT & $\begin{array}{l}\text { Ion channel disease: } \\
\text { diastolic sarcoplasmic } \\
\text { calcium leak }\end{array}$ & $35-50 \%$ & $78 \%$ & + & - & (9) \\
\hline IVF & Unknown & unknown & $>50 \%$ & ++ & - & (25) \\
\hline WPW & $\begin{array}{c}\text { Ventricular pre-excitation } \\
\text { through accessory AV } \\
\text { conduction pathway }\end{array}$ & unknown & $100 \%$ & - & +++ & (26) \\
\hline PCCD & $\begin{array}{l}\text { Accelerated fibrosis of the } \\
\text { conduction system }\end{array}$ & unknown & unknown & - & ++ & (29) \\
\hline $\mathrm{HCM}$ & $\begin{array}{l}\text { Mostly sarcomeric } \\
\text { dysfunction }\end{array}$ & $35-60 \%$ & $\begin{array}{l}\text { Age-related, nearly } \\
100 \% \text { at } \\
50-60 \text { years }\end{array}$ & ++ & + & (94) \\
\hline DCM & $\begin{array}{l}\text { Mostly sarcomeric } \\
\text { dysfunction }\end{array}$ & $25-40 \%$ & Age-related & - & - & (95) \\
\hline LVNC & Unknown & $17-41 \%$ & Unknown & + & - & (96) \\
\hline ARVC & $\begin{array}{l}\text { Myocardial fibrofatty } \\
\text { replacement }\end{array}$ & 60 & $\begin{array}{l}42 \%(A D), 97 \% \\
\text { (AR) }\end{array}$ & + & - & $(97,98)$ \\
\hline $\mathrm{RCM}$ & & Unknown & $\begin{array}{l}\text { Probable } \\
\text { age-related }\end{array}$ & + & + & (99) \\
\hline Marfan syndrome & $\begin{array}{l}\text { Microfibrillar deficiency } \\
\text { and TGF } \beta \text { dysregulation }\end{array}$ & $90-95 \%$ & $>90 \%$ & - & ++ & $(71)$ \\
\hline $\begin{array}{l}\text { Loeys-Dietz } \\
\text { syndrome }\end{array}$ & TGF $\beta$ dysregulation & $90 \%$ & $>90 \%$ & + & + & (79) \\
\hline FTAAD & $\begin{array}{c}\text { Vascular smooth muscle } \\
\text { contractile apparatus }\end{array}$ & $20 \%$ & $50 \%$ & unknown & + & (63) \\
\hline
\end{tabular}

CPVT, catecholaminergic polymorphic ventricular tachycardia; DCM, dilated cardiomyopathy; ERS, early repolarisation syndrome; FTAAD, familial thoracic aortic aneurysm and dissection; HCM, hypertrophic cardiomyopathy; IVF, idiopathic ventricular fibrillation; LVNC, left ventricular non-compaction; PCCD, progressive cardiac conduction disorder; RCM, restrictive cardiomyopathy; SCD, Sudden cardiac death; WPW, Wolff-Parkinson-White syndrome.

further characterized by congenital deafness and autosomal recessive inheritance. An acquired type of LQTS can be caused by adverse effects of drug therapy or electrolyte disturbances. An updated overview of all medications provoking LQT can be found at www.qtdrugs.org. Because several reports have shown a close relation between the structural properties of the hERG ion channel and its propensity for pharmacological interaction, it is believed that drug-induced LQT is rather a pharmacogenetic disease than a pure physicochemical drug interaction (11) (Table 1).

\section{Short QT syndrome}

The short QT syndrome (SQTS) is in many ways the mirror image of the LQTS. It is attributed to the pathological shortening of the APD, promoting both atrial and ventricular fibrillation (VF) resulting in high risk for SCD at young age. Although it is rare, already six genes have been identified (Table S1) $(10,12)$. The mode of inheritance is autosomal dominant.

A QTc $\leq 330 \mathrm{~ms}$ on the ECG is diagnostic for SQTS, usually with characteristic tall, peaked T-waves. In addition, the diagnosis should be considered if the 


\section{Genetics of SCD}

QTc $<360 \mathrm{~ms}$ in the presence of unexplained familial SCD $\leq 40$ years of age, familial history of SQTS or the identification of a pathogenic mutation (9).

\section{Brugada syndrome}

The Brugada syndrome (BrS) arises from ion channel dysfunctions that alter the early phases of the AP. The prevalence of BrS (type-1 ECG) is estimated at 1:2000 and is more prevalent in South-East Asia. BrS is diagnosed if a $\geq 2 \mathrm{~mm}$ cove-shaped ST elevation (type- 1 ECG) is found in at least one of the right precordial leads (V1-V2) with the electrodes in second, third or fourth intercostal space in baseline or during pharmacological provocation (9).

Several hypotheses have been postulated to explain its pathophysiology comprising increased AP dispersion within the right ventricular outflow tract (RVOT) epicardium due to changes in either repolarization or depolarization giving rise to the right precordial 'cove-shaped' ST elevations and promoting polymorphic VT and VF (13). In vivo evidence showed that the epicardial ablation of slow conduction sites could completely abolish the type-1 ECG characteristics demonstrating that $\mathrm{BrS}$ at least to some extent does require a structural substrate.

Currently 14 different genes have been identified (Table S1, Table 1) accounting for 18-32\% of all inherited $\mathrm{BrS}$ cases (14). Functionally, the majority directly or indirectly translate into a loss of function of the cardiac sodium current.

Acquired causes that trigger a Brugada phenotype have been identified as well (15). For updates on these medications, please consult www.brugadadrugs.org. Other conditions including hyper- and hypothermia, elevated insulin levels and mechanical compression of the RVOT have also been associated with an acquired $\mathrm{BrS}$.

\section{Early repolarisation syndrome}

Early repolarisation was first described as the occurrence of abnormal 'Osborn J-waves' on the ECG during hypothermia (16). The J-wave represents a J-point and ST segment elevation that is often seen as a notching or slurring of the terminal R-wave. It is attributed to the excessive dispersion of repolarisation that results from a disproportionate shortening of the epicardial APD with respect to endocardial APD. Later it was found that $\mathrm{J}$-waves are present in 1-2\% of the normal population and in up to $35 \%$ of athletes (17). Hence, the presence of J-waves in the precordial leads has been considered a benign phenomenon. However, the rare variants with inferior and/or lateral J-waves were found to be associated with idiopathic ventricular fibrillation (IVF), especially when the J-point elevation exceeded $2 \mathrm{~mm}$ and when discordant ST segment deviations were present in several leads (except aVR) (18).

The early repolarisation syndrome (ERS) is diagnosed in the presence of J-point elevation $\geq 1 \mathrm{~mm}$ in $\geq 2$ contiguous inferior and/or lateral leads in a patient with unexplained VF or polymorphic VT and might be suspected in the absence of such arrhythmias (9).
Currently six different genes have been associated with ERS (Table S1) (19). Early repolarisation is further associated with bradycardia, high vagal tone, hypothermia, hypercalcemia, short QT interval and electrocardiographic left ventricular hypertrophy.

\section{Catecholaminergic polymorphic ventricular tachycardia}

This is a rare disease responsible for polymorphic and often bidirectional VT in conditions of elevated adrenergic tone (20). The prevalence of catecholaminergic polymorphic ventricular tachycardia (CPVT) is unknown but roughly estimated at 1:10.000.

The baseline ECG is usually unremarkable and often shows relative bradycardia. However, when the heart rate rises by physical or emotional exertion, progressive multifocal ventricular ectopy develops that tends to become more polymorphic and sustained as the heart rate accelerates. In many cases, bidirectional VT develops, characterized by the beat-to-beat $180^{\circ}$ axis rotation of the QRS in a frontal plane. The arrhythmias can degenerate to VF and SCD (21). It was shown that this intricate adrenergic dependence of the arrhythmogenesis results from sarcoplasmic reticulum calcium overload provoking a rate-dependent diastolic calcium leak to the cytosol in turn resulting in elevated sodium-calcium exchanger activity and delayed after-depolarizations that trigger the arrhythmias.

CPVT is diagnosed when unexplained exercise- or catecholamine-induced bidirectional VT, polymorphic ventricular premature beats or VT is observed in an individual $<40$ years of age and should be considered when present in patients older than 40 if concomitant heart disease is absent (9).

At present, five loci have been implicated in the aetiology of CPVT (Table S1), representing $60 \%$ of inherited CPVT cases $(22,23)$. The autosomal dominant forms of CPVT caused by RYR2 (CPVT1) and CALM1 (CPVT3) are most prevalent, whereas $C A S Q 2$ (CPVT2) and TRDN (CPVT5) are rare and segregate in an autosomal recessive pattern. CPVT3 was mapped to $7 \mathrm{p} 22-\mathrm{p} 14$ but the culprit gene has not yet been identified (23).

\section{Idiopathic ventricular fibrillation}

IVF is a group of disorders that cause cardiac arrest preferentially by documented VF in the absence of detectable cardiac, respiratory, metabolic and toxicological reversible causes and when apparent structural or electrical heart disease could not be detected. Familial IVF has been associated with mutations in SCN5A (IVF1) (24) and in a Dutch founder population with DPP6 (IVF2) (25). The baseline ECG is usually unremarkable and VF tends to be triggered by short-coupled ventricular extrasystoles originating from a single focus. Others have described that ablation of these foci can at least temporarily alleviate the arrhythmia burden.

\section{Familial Wolff-Parkinson-White syndrome}

Wolf-Parkinson-White syndrome (WPW) represents an accessory conduction pathway between the atrium and 


\section{Saenen et al.}

ventricle, which can remain concealed or show as pre-excitation of the QRS complex (PR shortening and delta-wave appearance) on the ECG. WPW predisposes to atrioventricular (AV) reentrant tachycardia, hence, WPW causes palpitations, syncope and SCD. The occurrence of SCD results from atrial fibrillation with fast anterograde conduction over the accessory pathway. Recently, an autosomal dominant familial form of fasciculoventricular WPW associated with hypertrophic cardiomyopathy $(\mathrm{HCM})$ was identified. It was attributed to mutations in the PRKAG2 gene that encodes the AMP-activated protein kinase (AMPK; Table S1) (26).

\section{Progressive cardiac conduction disorder}

Progressive cardiac conduction disorder (PCCD), also known as Lenègre-Lev disease, is characterized by accelerated fibrotic degeneration of the cardiac conduction system. PCCD causes PR prolongation, QRS widening, bundle branch block and eventually total AV block at young age and therefore predisposes to syncope and $\mathrm{SCD}$. Often pacemaker implantation is required to prevent these consequences. Historically, two PCCD subtypes were identified in South African families showing an autosomal dominant inheritance. Type IA (PCCD-IA) is caused by mutations in SCN5A, whereas PCCD-IB was attributed to TRPM4 (Table S1) (27). In contrast, the genes responsible for type II PCCD remain elusive to date. Nowadays, new forms of hereditary PCCD have been associated with the NKX2-5, PRKAG2 and LMNA genes as well.

\section{Overlap syndromes}

Over the years, several clinical entities that combine traits of the above-described disorders were recognized. The overlap syndrome between BrS and SQTS showed ECG features that resemble BrS but with an additional short QTc interval (QTc $<360 \mathrm{~ms}$ ) and high risk for SCD (28). It was ascribed to loss-of-function mutations in the CACNA1C gene.

Also, specific mutations in SCN5A were responsible for LQT3 in some, while producing a BrS phenotype in others, conferring a LQTS-BrS overlap syndrome (29). Furthermore, it was suspected that ERS was related to $\mathrm{BrS}$ as it is characterized by similar ECG traits. Indeed, an early repolarisation pattern in the inferior or lateral leads was found in $11-15 \%$ of $\mathrm{BrS}$ patients. In this context, it was recognized that ERS, BrS and some forms of IVF all represent different expressions of a spectrum of disease with J-point abnormalities as common denominator, and therefore it was suggested to re-classify them as J-wave syndromes (JWS). Subsequently, it was shown that the cardiac sodium channel is involved in sick sinus syndrome (SSS), PCCD and atrial fibrillation (30). It becomes clear that the different PED are more related than previously assumed; the proteins that are involved in the various PED are interconnected through the cascade of proteins that form the cardiac AP, providing a plausible mechanism for these overlap syndromes.
To complicate things even more, a molecular overlap has been shown between PED and structural heart disease. SCN5A has been implicated in dilated cardiomyopathy (DCM), whereas CACNAIC underlies Timothy syndrome (LQTS8) that is a multi-system disorder comprising dysmorphic facial features, autism, syndactyly and arrhythmogenic electrical abnormalities (31). The emerging picture of these clinical and molecular overlap syndromes underlines the profound genetic pleiotropy that exists in the setting of the heterogeneous genotype-phenotype correlation. Both phenomena tremendously complicate clinical diagnosis as well as the application and interpretation of targeted genetic testing.

\section{Hereditary CM}

$\mathrm{CM}$ encompass a heterogeneous group of disorders that, much in contrast to the above-described PED, are characterized by structural remodelling of the cardiac muscle (32). These structural abnormalities cause a progressive loss of electrical stability of the cardiac tissue through the generation of anatomical arrhythmogenic substrate.

\section{Hypertrophic CM}

HCM is defined by asymmetric left ventricular thickening in the absence of abnormal afterload conditions (33). In most, the disease is inherited in an autosomal dominant manner. With an estimated prevalence of 1:500, $\mathrm{HCM}$ is the most common hereditary cardiovascular disorder (34). A major barrier in the clinical diagnosis of $\mathrm{HCM}$ is the variable age of onset of the hypertrophy and the incomplete penetrance of the phenotype (35). SCD occurs in $0.4-1 \%$ of HCM but subgroups with much higher incidence have been identified. Despite on-going technological advances, these high-risk patients cannot fully be distinguished from lower-risk individuals based on morphological criteria.

Several genes have been associated with HCM, >90\% of them encoding cardiac sarcomere proteins (Table S2). Mutations in genes that encode sarcomeric myofilament proteins (e.g. MYH7 and MYBPC3), Z-disc proteins (e.g. ACTN2 and MYOZ2) or calcium-handling proteins (JPH2, CASQ2) have been linked to HCM. Non-sarcomeric HCM include PRKAG2-related HCM, which was associated with familial WPW (fWPW). In patients with a genetic diagnosis, $70 \%$ have mutations in the two most common genes, beta-myosin heavy chain (MYH7) and myosin-binding protein $\mathrm{C}$ (MYBPC3), while other genes account for $1-5 \%$ of patients (Table $\mathrm{S} 2$, Table 1) (36). Compound mutations are found in approximately $7 \%$ of HCM, contributing to a worse phenotype and higher arrhythmogenic risk (37). In infants and children, HCM can be one aspect of syndromic disorders [e.g. Noonan's syndrome, LEOPARD syndrome (autosomal dominant) and Friedreich's ataxia (autosomal recessive)], inherited metabolic disorders and neuromuscular diseases.

Because of the clinical and genetic heterogeneity of HCM, genotype-phenotype correlations are weak. 
However, patients carrying a sarcomere mutation seem to present earlier, have more severe hypertrophy and have higher prevalence of a family history of the disease and SCD (38).

The exact mechanisms on how HCM develops as a consequence of sarcomere protein gene mutations are not completely understood. It has been hypothesized that sarcomere mutations alter calcium signalling, leading to activation of myocyte enhancer factor (Mef2) and increased TGF $\beta$ expression $(39,40)$. This in turn could stimulate fibroblast proliferation, a hallmark of HCM. Several mechanisms in HCM can lead to electrical disturbances. Myocyte disarray and fibrosis, characteristic in HCM, leads to pro-arrhythmogenic conduction delay (41). Second, studies in transgenic mice (troponin T-mutants) have shown that myofilament calcium sensitization induces functional re-entry circuits (42). Third, mutations in $M Y B P C 3$ inhibit physiological proteolytic degradation pathways and result in the accumulation of functional ion channels, disrupting the electrical stability of the heart (43).

\section{Dilated cardiomyopathy}

DCM is characterized by the pathologic enlargement of the ventricular cavities and impaired contractility in the absence of significant CAD and abnormal loading conditions $(33,44)$. The disease is associated with significant morbidity and mortality because of progression to terminal heart failure and to a lesser extent SCD. The incidence of DCM is estimated to be 5-8/100,000 with an observed prevalence of 1:2500 in adults (44).

Although the aetiology remains elusive in many cases, it is estimated that $50 \%$ of DCM cases are hereditary (45). To date, more than 40 genes have been implicated in familial DCM, leading to a huge genetic heterogeneity.

The pattern of inheritance may vary from autosomal dominant, over autosomal recessive to $\mathrm{X}$-linked and even matrilineal (46). Autosomal dominant forms are caused by sarcomeric proteins/Z-band, as well as nuclear envelope proteins, cytoskeletal proteins, ion channels and mitochondrial DNA-encoded genes (Table $\mathrm{S} 2$ ). Mutations in Lamin A/C are associated with conduction disturbances and account for $8 \%$ of familial DCM (47). Recently, mutations in the giant protein Titin (TTN) were identified in approximately $25 \%$ of familial cases of former idiopathic DCM (48). This elevated the total expected mutation detection rate to $>40 \%$ (48), although the distinction between true pathogenic variants and benign polymorphisms in TTN is particularly challenging. X-linked DCM is found in association with muscular dystrophies (Becker and Duchenne); however, dystrophin gene defects cause up to $7 \%$ of familial DCM in male patients, without overt skeletal myopathy (49).

In familial DCM, the onset of disease is gene-specific with PLN (phospholamban)-dependent DCM manifesting early in life, whereas LMNA (Lamin A/C) mutations, which comprise $0.5-5 \%$ of all DCM and over $33 \%$ of familial DCM, become clinically evident around the fourth decade. Furthermore, it is known that LMNA and $S C N 5 A$ mutation carriers are more prone to developing ventricular arrhythmias, conduction defects and SCD $(50,51)$. In contrast, $P L N$ mutation carriers usually display a rapid deterioration of the cardiac pump function (52). In this perspective, the early detection using genetic screening provides the opportunity to adopt a more tailored follow-up and custom treatment strategies for individual patients with DCM.

\section{Arrhythmogenic right ventricular cardiomyopathy}

In ARVC, fibrofatty infiltration progressively replaces contractile tissue leading to a reduction of the right ventricular function and progression to right ventricular aneurysm formation (33). Hence, in most cases, arrhythmias originating from the right ventricle present as the first symptom of the disease. The estimated prevalence of ARVC ranges between 1:5000 and 1:2000 (33). The disorder becomes clinically manifest during young adulthood and is a frequent cause of SCD in young adults. Incomplete penetrance with 3 to 1 male preponderance suggests that sex hormones might play a role in the clinical phenotype.

ARVC can be divided into a desmosomal and non-desmosomal subtype. The pathophysiology of desmosomal ARVC comprises a progressive loss of cell-to-cell coupling of the cardiac myocytes promoting apoptosis and inducing fibrofatty replacement. To date, six genes (Table S2) have been implicated in this subtype $(53,54)$. The pattern of inheritance in the majority of cases is autosomal dominant but rare autosomal recessive forms (e.g. JUP) of ARVC exist as well.

The less common non-desmosomal ARVC subtype is attributed to heterozygous mutations in the cardiac ryanodine receptor ( $R Y R 2)$, transforming growth factor- $\beta-3$ $(T G F-\beta 3)$ or transmembrane protein 43 (TMEM43) and alpha-3 catenin (CTTNA3) genes comprising different pathophysiological mechanisms ranging from disruption of intracellular calcium handling, over altered regulation of extracellular matrix production to dysregulation of the adipogenic pathway (55-57). Finally, it is suspected that some forms of ARVC may be induced by life-long-intensive physical exercise.

\section{Left ventricular non-compaction}

Left ventricular non-compaction (LVNC) is characterized by prominent left ventricular trabeculae and deep intertrabecular recesses, leading to increased thrombi-embolic risk and stroke. In some patients, LVNC is associated with left ventricular dilation and decreased contractile function.

A clinical distinction is made between isolated (solely affecting the heart) and non-isolated LVNC as part of a larger clinical syndrome (e.g. congenital cardiac disorders and neuromuscular disease) (33). The reported prevalence of isolated LVNC in the general population is $0.26 \%$ and amounts to $3.7 \%$ in those with a left ventricular ejection fraction of $\leq 45 \%$. Although the genetic diagnosis remains elusive in almost half of LVNC, most cases display an autosomal dominant transmission, although cases with X-linked inheritance have been recognized. 


\section{Saenen et al.}

To date, 15 disease-causing genes have been identified (Table S2), often with a shared molecular aetiology with HCM and DCM. The gene products are involved in intracellular calcium handling (e.g. calsequestrin and phospholamban), sarcomeric myofilament formation (e.g. troponine I and troponine T), transmembrane ion conductance (e.g. hERG and Nav1.5), nuclear envelope formation (e.g. Lamin A/C) and others ( $\alpha$-dystrobrevin, tafazzin and Cypher/ZASP) $(58,59)$. Reminiscent of HCM, compound mutations, accounting for up to $10 \%$ of adult LVNC patients, are most often found in genes encoding sarcomeric proteins (60).

\section{Restrictive cardiomyopathy}

Restrictive cardiomyopathy (RCM) is a rare condition that causes a progressive stiffening of the cardiac wall hampering diastolic relaxation in the presence of normal or reduced systolic and/or diastolic volumes and in the absence of significant left ventricular hypertrophy (33). In early stages of RCM, diastolic dysfunction is on the forefront, but as the disease progresses systolic function is usually affected as well.

Troponinopathies and desminopathies are typical in RCM and display a distinct phenotype: the conduction system is usually not affected in troponinopathies, whereas desminopathies are associated with AV block and skeletal myopathy (61). This clinical distinction is important, as troponinopathies confer a high arrhythmogenic risk, which is negligible in desminopathies (62).

\section{Thoracic aortic aneurysm and dissection}

If left untreated, aortic aneurysms evolve towards dissection and rupture. The current belief is that $2-3$ times as many patients die from thoracic aortic dissection when compared with ruptured abdominal aorta. Upon the rupture of an abdominal aortic aneurysm, up to $75 \%$ make it to the emergency room alive. In the case of a TAAD, $40 \%$ die immediately with an hourly death rate of $1 \%$ thereafter (63). Furthermore, it was shown that hereditary aortic aneurysm disease is associated with ventricular arrhythmias, indicating that death in these patients does not solely result from the rupture of the aortic vessel (64-66). Mortality after TAAD reaches $97 \%$ with a median survival rate of 3 days (67). As such, aortic dissection represents an important cause of death $(1-2 \%)$ and needs to incorporated in the SCD work-up. Importantly, the genetic contribution to thoracic aortic aneurysm (TAA) is significant as $20 \%$ of all affected individuals have a positive family history. As many family members may not be aware of the presence of an aneurysm, the latter figure is likely to be underestimated (68). Although in abdominal aortic aneurysm several predisposing genetic variants have been identified (e.g. LRP1, variants in RAAS, ... ), risk factors such as smoking, hypertension and hypercholesterolemia play an important role. Overall, a genetic cause of TAA can be identified in circa $30 \%$ of all probands (Table S3). In general, two major pathogenic themes have emerged over the last decade: vascular smooth muscle cell (VSMC) specific sarcomeric protein dysfunction and dysregulation of transforming growth factor beta (TGF $\beta$ ) signalling (69). Within the non-syndromic forms, multiple genes coding for components of the VSMC contractile apparatus $(A C T A 2, M Y H 11, \ldots)$ have been identified, whereas within the syndromic forms mutations in genes encoding components of the extracellular matrix (e.g. fibrillin- 1 , collagen $3, \ldots$ ) and the TGF $\beta$ signalling cascade $(T G F B R 1 / 2, S M A D 3, \ldots)$ are the culprit.

\section{Marfan syndrome}

Marfan syndrome (MFS) is an autosomal dominant connective tissue disorder with an estimated prevalence of 1/5.000-1/3.000. About two thirds of patients have a positive family history, whereas one third is the consequence of a de novo mutation. This pleiotropic disease predominantly affects three organ systems: ocular (ectopia lentis), skeletal (overgrowth) and cardiovascular (aortic aneurysm and dissection). The condition is caused by mutations in the FBN1 gene, encoding fibrillin-1, an important extracellular component of the microfibrils. With the current mutation detection techniques, a causal mutation can be identified in circa $90 \%$ of the probands. Deep intronic, promotor and untranslated regions might harbour the missing $10 \%$ of FBN1 mutations. Over the years, thousands of different $F B N 1$ mutations have been identified, but no major genotype-phenotype correlations have emerged (70). The phenotype is characterized by a large intra- and interfamilial variability. A set of clinical diagnostic criteria has been defined in the revised nosology (71). This new nosology has simplified the diagnostic decision-making process and also offers handles for differential diagnosis and management.

The study Marfan mouse models has opened a new era in the understanding of the aetiology of this condition (72). MFS is no longer a pure structural deficiency of an extracellular matrix protein but has evolved towards a disease that is tightly linked to dysregulated TGF $\beta$ signalling, rendering it amenable for new treatment interventions, such as angiotensin receptor blockers $(73,74)$.

\section{Loeys-Dietz syndrome - aneurysm-osteo-arthritis syndrome}

Loeys-Dietz syndrome (LDS) is an autosomal dominant connective tissue disorder with multi-systemic involvement. The most typical clinical triad consists of hypertelorism, cleft palate/bifid uvula and arterial tortuosity with widespread aggressive aortic/arterial aneurysms. Initially, two causal genes were identified: transforming growth factor beta receptors 1 and 2 (TGFBR1/2) (75). More recently two other genes, SMAD3 and TGFB2, were reported in clinical presentations with significant clinical overlap with LDS. SMAD3 mutations were found in patients with aneurysm-osteo-arthritis syndrome (AOS) that demonstrated a lot of common features with LDS including hypertelorism, bifid uvula, arterial tortuosity and widespread aneurysms (76). Since the initial report, patients with SMAD3 mutations but without 


\section{Genetics of SCD}

osteoarthritis have been reported. Similarly, although TGFB2 mutations were identified in patients with MFS-like phenotypes (77), other patients had clinical pictures very reminiscent of LDS (78). Importantly, aortic tissues of LDS patients with loss-of-function mutations in either of these four genes showed increased TGF $\beta$ signalling. In LDS, dissections have been described at aortic diameters as small as $4 \mathrm{~cm}$. As such, one should consider earlier aortic surgery in LDS patients, taking into account rate of progression, family history, aortic valve function and available literature. Specific diagnostic and management guidelines have recently been published (79).

\section{Ehlers-Danlos syndrome}

Ehlers-Danlos syndrome (EDS) is a heterogeneous group of disorders mainly characterized by skin (hyperextensibility), joint (hypermobility, luxations) and vascular (arterial rupture) findings. Three main subtypes have been delineated: the classic type (mostly affecting skin), the hypermobile type (predominant joint involvement) and the vascular type (Villefranche nosology) (80). The latter form is caused by a deficiency of type III collagen (encoded by COL3AI) and is mainly characterized by hypermobility of the small joints (especially hands), thin rather than hyperextensible skin and ruptures of hollow organs and the arterial system. Most typically, it affects medium-sized arteries, but dissections of the aorta have also been described. Mutations in COL3A1 leading to haplo-insufficiency lead to a milder phenotype, while missense mutations replacing critical glycine residues present with more severe phenotypes. Unfortunately, the clinical diagnosis is often missed until a life-threatening event (hollow organ or arterial rupture) occurs and final diagnosis is relying on the identification of a COL3A1 mutation. Up to $50 \%$ of patients lack a family history. Their disease is caused by de novo mutations (81).

\section{Non-syndromic aortic aneurysm syndrome}

Some genes, previously associated with syndromic forms of aortic aneurysm/dissection (TGFBR2, SMAD3, $F B N 1$ ), have also been implicated in non-syndromic forms of aortic aneurysm. Many of these families, however, displayed some skeletal features and may thus represent the mildest end of the spectrum of syndromic forms. Mutations in genes encoding components of the VSMC contractile apparatus typically lead to non-syndromic familial thoracic aortic aneurysm and dissection (FTAAD). The most common form, accounting for up to $14 \%$, is caused by mutations in ACTA2, encoding a VSMC specific actin (82). Mutations in $M Y H 11$ (myosin heavy chain 11) account for TAA in association with patent ductus arteriosus (83). Finally, rare mutations $(<1 \%)$ in $M Y L K$ or PRKG1, two modifiers of myosin function have been identified (84).

Although the mutations in ACTA2, MYH11, MYLK and PRKG1 primarily affect VSMC function, upregulation of TGF $\beta$ signalling has also been observed in aortic walls of
TAA patients with ACTA2 and MYH11 mutations (85). Cell surface integrins, linked to VSMC contractile apparatus through the intermediate and well-known regulators of TGF $\beta$ activity, might explain this finding.

\section{Bicuspid aortic valve-related aneurysm}

Bicuspid aortic valve (BAV) is the most common congenital cardiac malformation affecting $1-2 \%$ of the population with a $3 / 1$ male predominance (86). More than $35 \%$ of BAV patients will develop serious aortic complications, including valve regurgitation, aortic stenosis, TAA and aortic dissections. The risk of aortic dissection in BAV patients is almost nine times higher and occurring at a younger age when compared with individuals with a tricuspid aortic valve (87). The inheritance pattern of BAV is most consistent with an autosomal dominant mode of transmission with reduced penetrance and variable expressivity. While the heritability of BAV is now well established, genes linked to the defect remain largely unknown (88). Several studies suggest a high locus heterogeneity for BAV-associated TAA.

\section{Discussion and future perspectives}

The genetic testing was recently revolutionized by the advent of next generation sequencing. In order to benefit from this technological feat, an integrated cardiological and genetic approach is required. Different models for cardiogenetic clinics can be imagined but ideally a joined consultation addressing both genetic and cardiological questions is organized. This approach integrates the detailed study of pedigree and family history, old clinical records, clinical investigations of the proband and its first-degree relatives with broad genetic testing. Over the last years, this testing has moved from a candidate gene-by-gene strategy to a more comprehensive multiple gene approach. In many countries, next generation sequencing-based multigene panels are now offered for dedicated genetic testing. These may include groups of disorders (e.g. PED genes) or even sets including all known SCD-related genes. Others are using exome sequencing with a post hoc targeted analysis of clinically relevant genes. The latter approach has the disadvantage that it will not cover circa $10 \%$ of the relevant coding regions. Analysis of these multigene panels will lead to a more comprehensive view of all existing genetic variation and its ability to modify phenotypes. This is often a challenging task and may not always lead to an unequivocal decision. The tabulation of all genetic variation will require further international collaboration and registries. In addition, although many predictive tools for empirical prediction of mutation impact exist, we will have to develop better functional tools to study the effect of genetic variants.

Although the correlation between genotype and the resulting phenotype in symptomatic patients is often evident, the genotype-phenotype correlation is often lacking or remains unpredictable in asymptomatic individuals. For instance, when TAA occurs in a syndromic context, the molecular diagnosis is usually quite 
straightforward as only a limited number of genes are involved (e.g. FBN1 for MFS), and a careful work-up of the pathognomonic clinical signs by an experienced clinical geneticist can guide the selection of the most likely candidate gene. However, it is becoming more difficult in genetic heterogeneous conditions such as LDS, where four causal genes (TGFBR1/2, SMAD3, TGFB2) have been implicated. In patients with less prominent clinical signs or children that present with evolving phenotypes, it is far from obvious to make a correct molecular diagnosis. Moreover, several genes show a diverging range of phenotypes. For example, mutations in TGFBR 1 and TGFBR2 have been identified in isolated TAA (89), while mutations in TGFBR2 can cause a MFS-related phenotype (90). Similar pleiotropy has been described for both CM and PED with the existence of clinical and molecular overlap syndromes on the one hand and profound phenotypical heterogeneity on the other hand, as one mutation can lead to different forms of CM or PED. Even among different members of the same family, the phenotypes range from full-blown disease to an entirely asymptomatic course of life.

Probably the most important determinant of variable expressivity is the fact that many of the inherited cardiac diseases are complex polygenic diseases requiring more than one genetic and/or acquired 'hit' to trigger the clinical phenotype. In PED, the alternative splicing of gene transcripts, heteromeric assembly of ion channel subunits and interactions with auxiliary proteins that mediate protein folding, trafficking and anchoring in the plasma membrane create different layers of complexity. Similarly, the contractile apparatus as well as the cytoskeleton of the myocyte and the VSMC depend on the integrity of multiple proteins. From this perspective, it is to be expected that one disease phenotype may arise from different genes, while at the same time it may be that deficiency of one gene product may not be sufficient to cause disease. Examples of severe phenotypes arising from digenic mutations have been reported, although it is suspected that many more cases with less extreme phenotypes have gone unrecognized because of the predominant use of gene-by-gene sequencing techniques (91). In addition, common single nucleotide polymorphisms (SNPs) can amplify or reduce the effects of known pathogenic mutations (92). Moreover, gene expression is influenced by factors including age, left ventricular hypertrophy and heart failure resulting in structural and electrical remodelling of the heart. Consequently, it is likely that the genetic constitution of an individual is dynamic over time by means of changes in expression, implying that the resultant intrinsic risk for SCD might change accordingly.

We are only beginning to understand the complexity of variable expressivity; therefore, extreme caution should be exercised when counselling patients and relatives with inherited cardiac diseases. Next generation sequencing will allow a more differentiated identification of the individual's genotype and guide a more gene-tailored patient management. However, such approach is a double-edged sword as distinguishing pathogenic mutations from disease modifiers, normal variation and background noise without functional information remain a probabilistic process at best with already countless exceptions against generally accepted rules and algorithm predictions published. In a recent expert consensus, referral of all SCD survivors with suspected PED and their first-degree relatives to dedicated cardiogenetic clinics for evaluation has become a class I recommendation (9). Obviously, this is equally important in the group of CM and TAA.

The gap that perseveres between the genetic and clinical reality needs to be bridged by better systematic functional analysis as this will provide the necessary insight into the impact a variant imposes on pathophysiology. Historically, patch clamp techniques have been widely adopted to functionally assess PED cases, but the analysis is notoriously labour intensive. Moreover, these assays are available in only a handful specialized labs, and therefore these functional analysis have never reached routine application for clinical practice. The systematic study of the impact of molecular abnormalities on the structural integrity of the contractile apparatus or connective tissue is even more challenging. Recently, great progress has been gained by the use of induced pluripotent stem cells (IPS) for both PED and CM. The technique is promising as it allows the assessment of the electrical properties and the structural integrity of the myocyte against the entire genetic background of a given patient. Further study and validation will show whether this approach will prove fit for clinical practice.

\section{Supporting Information}

Additional supporting information may be found in the online version of this article at the publisher's web-site.

\section{Acknowledgements}

B. L. L. is senior clinical investigator of the Fund for Scientific Research, Flanders (FWO, Belgium). This research was supported by funding from the Fund for Scientific Research, Flanders (FWO, Belgium) [G.0458.09; G.0221.12], the Fondation Leducq, the European Research Council (ERC), the University of Antwerp (Lancerings project).

\section{References}

1. Straus SM, Bleumink GS, Dieleman JP, van der Lei J, Stricker BH, Sturkenboom MC. The incidence of sudden cardiac death in the general population. J Clin Epidemiol 2004: 57 (1): 98-102.

2. Goldberger JJ, Cain ME, Hohnloser SH et al. American Heart Association/American College of Cardiology Foundation/Heart Rhythm Society scientific statement on noninvasive risk stratification techniques for identifying patients at risk for sudden cardiac death: a scientific statement from the American Heart Association Council on Clinical Cardiology Committee on Electrocardiography and Arrhythmias and Council on Epidemiology and Prevention. Circulation 2008: 118 (14): 1497-1518.

3. Huikuri HV, Castellanos A, Myerburg RJ. Sudden death due to cardiac arrhythmias. N Engl J Med 2001: 345 (20): 1473-1482.

4. Hendrix A. Sudden cardiac death in the young: incidence and consequences. Utrecht: University of Utrecht, 2011.

5. Hendrix A, van der Werf C, Bots ML et al. Rationale and design of the CAREFUL study: the yield of CARdiogenetic scrEening in First degree relatives of sudden cardiac and UnexpLained death victims $<45$ years. Neth Heart J 2010: 18 (6): 286-290.

6. Ackerman MJ, Priori SG, Willems S et al. HRS/EHRA expert consensus statement on the state of genetic testing for the channelopathies 


\section{Genetics of SCD}

and cardiomyopathies: this document was developed as a partnership between the Heart Rhythm Society (HRS) and the European Heart Rhythm Association (EHRA). Europace 2011: 13 (8): 1077-1109. DOI 10.1093/europace/eur245.

7. Behr ER, Dalageorgou C, Christiansen $M$ et al. Sudden arrhythmic death syndrome: familial evaluation identifies inheritable heart disease in the majority of families. Eur Heart J 2008: 29 (13): 1670-1680.

8. van der Werf C, Hofman N, Tan HL et al. Diagnostic yield in sudden unexplained death and aborted cardiac arrest in the young: the experience of a tertiary referral center in The Netherlands. Heart Rhythm 2010: 7 (10): 1383-1389.

9. Priori SG, Wilde AA, Horie M et al. HRS/EHRA/APHRS expert consensus statement on the diagnosis and management of patients with inherited primary arrhythmia syndromes: document endorsed by HRS, EHRA, and APHRS in May 2013 and by ACCF, AHA, PACES, and AEPC in June 2013. Heart Rhythm 2013: 10 (12): 1932-1963. DOI 10.1016/j.hrthm.2013.05.014.

10. Hedley PL, Jorgensen P, Schlamowitz S et al. The genetic basis of long QT and short QT syndromes: a mutation update. Hum Mutat 2009: 30 (11): 1486-1511.

11. Fitzgerald PT, Ackerman MJ. Drug-induced torsades de pointes: the evolving role of pharmacogenetics. Heart Rhythm 2005: 2 (2 Suppl): S30-S37. DOI: 10.1016/j.hrthm.2005.08.007.

12. Templin C, Ghadri JR, Rougier JS et al. Identification of a novel loss-of-function calcium channel gene mutation in short QT syndrome (SQTS6). Eur Heart J 2011: 32 (9): 1077-1088. DOI: 10.1093/eurheartj/ehr076.

13. Antzelevitch C, Nof E. Brugada syndrome: recent advances and controversies. Curr Cardiol Rep 2008: 10 (5): 376-383.

14. Ishikawa T, Takahashi N, Ohno S et al. Novel SCN3B mutation associated with brugada syndrome affects intracellular trafficking and function of Nav1.5. Circ J 2013: 77 (4): 959-967.

15. Shimizu W. Acquired forms of the Brugada syndrome. J Electrocardiol 2005: 38 (4 Suppl): 22-25.

16. Antzelevitch C, Yan GX. J wave syndromes. Heart Rhythm 2010: 7 (4): 549-558. DOI: 10.1016/j.hrthm.2009.12.006.

17. Noseworthy PA, Weiner R, Kim J et al. Early repolarization pattern in competitive athletes: clinical correlates and the effects of exercise training. Circ Arrhythm Electrophysiol 2011: 4 (4): 432-440. DOI 10.1161/CIRCEP.111.962852.

18. Rosso R, Glikson E, Belhassen B et al. Distinguishing "benign" from "malignant early repolarization": the value of the ST-segment morphology. Heart Rhythm 2012: 9 (2): 225-229. DOI: 10.1016/j.hrthm.2011.09.012.

19. Antzelevitch C. Genetic, molecular and cellular mechanisms underlying the J wave syndromes. Circ J 2012: 76 (5): 1054-1065.

20. Mohamed U, Napolitano C, Priori SG. Molecular and electrophysiological bases of catecholaminergic polymorphic ventricular tachycardia. J Cardiovasc Electrophysiol 2007: 18 (7): 791-797.

21. Priori SG, Chen SR. Inherited dysfunction of sarcoplasmic reticulum Ca2+ handling and arrhythmogenesis. Circ Res 2011: 108 (7): 871-883. DOI: 10.1161/CIRCRESAHA.110.226845.

22. Bai R, Napolitano C, Bloise R, Monteforte N, Priori SG. Yield of genetic screening in inherited cardiac channelopathies: how to prioritize access to genetic testing. Circ Arrhythm Electrophysiol 2009: 2 (1): 6-15.

23. Bhuiyan ZA, Hamdan MA, Shamsi ET et al. A novel early onset lethal form of catecholaminergic polymorphic ventricular tachycardia maps to chromosome 7p14-p22. J Cardiovasc Electrophysiol 2007: 18 (10): 1060-1066. DOI: 10.1111/j.1540-8167.2007.00913.x.

24. Akai J, Makita N, Sakurada $\mathrm{H}$ et al. A novel SCN5A mutation associated with idiopathic ventricular fibrillation without typical ECG findings of Brugada syndrome. FEBS Lett 2000: 479 (1-2): 29-34.

25. Postema PG, Christiaans I, Hofman $\mathrm{N}$ et al. Founder mutations in the Netherlands: familial idiopathic ventricular fibrillation and DPP6. Neth Heart J 2011: 19 (6): 290-296. DOI: 10.1007/s12471-011-0102-8.

26. Gollob MH, Green MS, Tang AS et al. Identification of a gene responsible for familial Wolff-Parkinson-White syndrome. N Engl J Med 2001: 344 (24): 1823-1831. DOI: 10.1056/NEJM200106143442403.

27. Kruse M, Schulze-Bahr E, Corfield V et al. Impaired endocytosis of the ion channel TRPM4 is associated with human progressive familia heart block type I. J Clin Invest 2009: 119 (9): 2737-2744. DOI: 10.1172/JCI38292.

28. Antzelevitch C, Pollevick GD, Cordeiro JM et al. Loss-of-function mutations in the cardiac calcium channel underlie a new clinical entity characterized by ST-segment elevation, short QT intervals, and sudden cardiac death. Circulation 2007: 115 (4): 442-449.

29. Makita N, Behr E, Shimizu W et al. The E1784K mutation in SCN5A is associated with mixed clinical phenotype of type 3 long QT syndrome. J Clin Invest 2008: 118 (6): 2219-2229. DOI: 10.1172/JCI34057.

30. Smits JP, Koopmann TT, Wilders R et al. A mutation in the human cardiac sodium channel $(\mathrm{E} 161 \mathrm{~K})$ contributes to sick sinus syndrome, conduction disease and Brugada syndrome in two families. J Mol Cell Cardiol 2005: 38 (6): 969-981. DOI: 10.1016/j.yjmcc.2005.02.024.

31. Napolitano C, Antzelevitch C. Phenotypical manifestations of mutations in the genes encoding subunits of the cardiac voltage-dependent L-type calcium channel. Circ Res 2011: 108 (5): 607-618. DOI: 10.1161/CIRCRESAHA.110.224279.

32. Arbustini E, Narula N, Dec GW et al. The MOGE(S) classification for phenotype-genotype nomenclature of cardiomyopathy: endorsed by the World Heart Federation. J Am Coll Cardiol 2013: 62 (22): 2046-2072. DOI: $10.1016 /$ j.jacc.2013.08.1644.

33. Elliott $\mathrm{P}$, Andersson B, Arbustini E et al. Classification of the cardiomyopathies: a position statement from the European Society of Cardiology Working Group on Myocardial and Pericardial Diseases. Eur Heart J 2008: 29 (2): 270-276.

34. Morita H, Larson MG, Barr SC et al. Single-gene mutations and increased left ventricular wall thickness in the community: the Framingham Heart Study. Circulation 2006: 113 (23): 2697-2705.

35. Charron P, Carrier L, Dubourg O et al. Penetrance of familial hypertrophic cardiomyopathy. Genet Couns 1997: 8 (2): 107-114.

36. Maron BJ, Maron MS, Semsarian C. Genetics of hypertrophic cardiomyopathy after 20 years: clinical perspectives. J Am Coll Cardiol 2012: 60 (8): 705-715. DOI: 10.1016/j.jacc.2012.02.068.

37. Morita H, Rehm HL, Menesses A et al. Shared genetic causes of cardiac hypertrophy in children and adults. N Engl J Med 2008: 358 (18): 1899-1908

38. Lopes LR, Rahman MS, Elliott PM. A systematic review and meta-analysis of genotypephenotype associations in patients with hypertrophic cardiomyopathy caused by sarcomeric protein mutations Heart 2013: 99 (24): 1800-1811. DOI: 10.1136/heartjnl-2013-303939.

39. Konno T, Chen D, Wang L et al. Heterogeneous myocyte enhancer factor-2 (Mef2) activation in myocytes predicts focal scarring in hypertrophic cardiomyopathy. Proc Natl Acad Sci USA 2010: 107 (42): 18097-18102. DOI: 10.1073/pnas.1012826107.

40. Teekakirikul P, Eminaga S, Toka O et al. Cardiac fibrosis in mice with hypertrophic cardiomyopathy is mediated by non-myocyte proliferation and requires Tgf-beta. J Clin Invest 2010: 120 (10): 3520-3529. DOI 10.1172/JCI42028.

41. Saumarez RC, Camm AJ, Panagos A et al. Ventricular fibrillation in hypertrophic cardiomyopathy is associated with increased fractionation of paced right ventricular electrograms. Circulation 1992: 86 (2) 467-474.

42. Baudenbacher F, Schober T, Pinto JR et al. Myofilament Ca2+ sensitization causes susceptibility to cardiac arrhythmia in mice. J Clin Invest 2008: 118 (12): 3893-3903. DOI: 10.1172/JCI36642.

43. Bahrudin U, Morikawa K, Takeuchi A et al. Impairment of ubiquitin-proteasome system by E334K cMyBPC modifies channel proteins, leading to electrophysiological dysfunction. J Mol Biol 2011: 413 (4): 857-878. DOI: 10.1016/j.jmb.2011.09.006.

44. Jefferies JL, Towbin JA. Dilated cardiomyopathy. Lancet 2010: 375 (9716): 752-762. DOI: 10.1016/S0140-6736(09)62023-7.

45. Charron P, Arad M, Arbustini E et al. Genetic counselling and testing in cardiomyopathies: a position statement of the European Society of Cardiology Working Group on Myocardial and Pericardial Diseases. Eur Heart J 2010: 31 (22): 2715-2726. DOI: 10.1093/eurheartj/ ehq271.

46. Grunig E, Tasman JA, Kucherer H, Franz W, Kubler W, Katus HA. Frequency and phenotypes of familial dilated cardiomyopathy. J Am Coll Cardiol 1998: 31 (1): 186-194.

47. Kamisago M, Sharma SD, DePalma SR et al. Mutations in sarcomere protein genes as a cause of dilated cardiomyopathy. N Engl J Med 2000: 343 (23): 1688-1696.

48. Herman DS, Lam L, Taylor MR et al. Truncations of titin causing dilated cardiomyopathy. N Engl J Med 2012: 366 (7): 619-628. DOI: 10.1056/NEJMoa1110186

49. Arbustini E, Diegoli M, Morbini P et al. Prevalence and characteristics of dystrophin defects in adult male patients with dilated cardiomyopathy. J Am Coll Cardiol 2000: 35 (7): 1760-1768. 
50. Pasotti M, Klersy C, Pilotto A et al. Long-term outcome and risk stratification in dilated cardiolaminopathies. J Am Coll Cardiol 2008: 52 (15): 1250-1260.

51. McNair WP, Ku L, Taylor MR et al. SCN5A mutation associated with dilated cardiomyopathy, conduction disorder, and arrhythmia. Circulation 2004: 110 (15): 2163-2167.

52. Schmitt JP, Kamisago M, Asahi M et al. Dilated cardiomyopathy and heart failure caused by a mutation in phospholamban. Science 2003: 299 (5611): 1410-1413.

53. van Tintelen JP, Hofstra RM, Wiesfeld AC, van den Berg MP, Hauer RN, Jongbloed JD. Molecular genetics of arrhythmogenic right ventricular cardiomyopathy: emerging horizon? Curr Opin Cardiol 2007: 22 (3): 185-192.

54. Quarta G, Syrris P, Ashworth M et al. Mutations in the Lamin A/C gene mimic arrhythmogenic right ventricular cardiomyopathy. Eur Heart J 2012: 33 (9): 1128-1136. DOI: 10.1093/eurheartj/ehr451.

55. Beffagna G, Occhi G, Nava A et al. Regulatory mutations in transforming growth factor-beta3 gene cause arrhythmogenic right ventricular cardiomyopathy type 1. Cardiovasc Res 2005: 65 (2): 366-373.

56. Tiso N, Stephan DA, Nava A et al. Identification of mutations in the cardiac ryanodine receptor gene in families affected with arrhythmogenic right ventricular cardiomyopathy type 2 (ARVD2). Hum Mol Genet 2001: 10 (3): 189-194.

57. Merner ND, Hodgkinson KA, Haywood AF et al. Arrhythmogenic right ventricular cardiomyopathy type 5 is a fully penetrant, lethal arrhythmic disorder caused by a missense mutation in the TMEM43 gene. Am J Hum Genet 2008: 82 (4): 809-821.

58. Ichida F, Tsubata S, Bowles KR et al. Novel gene mutations in patients with left ventricular noncompaction or Barth syndrome. Circulation 2001: 103 (9): 1256-1263.

59. Xing Y, Ichida F, Matsuoka T et al. Genetic analysis in patients with left ventricular noncompaction and evidence for genetic heterogeneity. Mol Genet Metab 2006: 88 (1): 71-77.

60. Hoedemaekers YM, Caliskan K, Michels M et al. The importance of genetic counseling, DNA diagnostics, and cardiologic family screening in left ventricular noncompaction cardiomyopathy. Circ Cardiovasc Genet 2010: 3 (3): 232-239.

61. Arbustini E, Pasotti M, Pilotto A et al. Desmin accumulation restrictive cardiomyopathy and atrioventricular block associated with desmin gene defects. Eur J Heart Fail 2006: 8 (5): 477-483. DOI: 10.1016/j.ejheart.2005.11.003.

62. Fiset $\mathrm{C}$, Giles WR. Cardiac troponin $\mathrm{T}$ mutations promote life-threatening arrhythmias. J Clin Invest 2008: 118 (12): 3845-3847. DOI: $10.1172 / \mathrm{JCI} 37787$.

63. Hiratzka LF, Bakris GL, Beckman JA et al. 2010 ACCF/AHA/AATS/ ACR/ASA/SCA/SCAI/SIR/STS/SVM guidelines for the diagnosis and management of patients with Thoracic Aortic Disease: a report of the American College of Cardiology Foundation/American Heart Association Task Force on Practice Guidelines, American Association for Thoracic Surgery, American College of Radiology, American Stroke Association, Society of Cardiovascular Anesthesiologists, Society for Cardiovascular Angiography and Interventions, Society of Interventional Radiology, Society of Thoracic Surgeons, and Society for Vascular Medicine. Circulation 2010: 121 (13): e266-e369. DOI: 10.1161/CIR.0b013e3181d4739e.

64. Aydin A, Adsay BA, Sheikhzadeh S et al. Observational cohort study of ventricular arrhythmia in adults with Marfan syndrome caused by FBN1 mutations. PLoS One 2013: 8 (12): e81281. DOI: 10.1371/journal.pone.0081281.

65. Yetman AT, Bornemeier RA, McCrindle BW. Long-term outcome in patients with Marfan syndrome: is aortic dissection the only cause of sudden death? J Am Coll Cardiol 2003: 41 (2): 329-332.

66. Hoffmann BA, Rybczynski M, Rostock T et al. Prospective risk stratification of sudden cardiac death in Marfan's syndrome. Int J Cardiol 2013: 167 (6): 2539-2545. DOI: 10.1016/j.ijcard.2012.06.036.

67. Johansson G, Markstrom U, Swedenborg J. Ruptured thoracic aortic aneurysms: a study of incidence and mortality rates. J Vasc Surg 1995: 21 (6): 985-988.

68. Elefteriades JA, Farkas EA. Thoracic aortic aneurysm clinically pertinent controversies and uncertainties. J Am Coll Cardiol 2010: 55 (9): $841-857$.

69. Gillis E, Van Laer L, Loeys BL. Genetics of thoracic aortic aneurysm: at the crossroad of transforming growth factor-beta signaling and vascular smooth muscle cell contractility. Circ Res 2013: 113 (3): 327-340. DOI: 10.1161/CIRCRESAHA.113.300675.
70. Faivre L, Collod-Beroud G, Loeys BL et al. Effect of mutation type and location on clinical outcome in 1,013 probands with Marfan syndrome or related phenotypes and FBN1 mutations: an international study. Am J Hum Genet 2007: 81 (3): 454-466. DOI: 10.1086/520125.

71. Loeys BL, Dietz HC, Braverman AC et al. The revised Ghent nosology for the Marfan syndrome. J Med Genet 2010: 47 (7): 476-485.

72. Neptune ER, Frischmeyer PA, Arking DE et al. Dysregulation of TGF-beta activation contributes to pathogenesis in Marfan syndrome. Nat Genet 2003: 33 (3): 407-411.

73. Habashi JP, Doyle JJ, Holm TM et al. Angiotensin II type 2 receptor signaling attenuates aortic aneurysm in mice through ERK antagonism. Science 2011: 332 (6027): 361-365.

74. Brooke BS, Habashi JP, Judge DP, Patel N, Loeys B, Dietz HC 3rd.. Angiotensin II blockade and aortic-root dilation in Marfan's syndrome. N Engl J Med 2008: 358 (26): 2787-2795.

75. Loeys BL, Chen J, Neptune ER et al. A syndrome of altered cardiovascular, craniofacial, neurocognitive and skeletal development caused by mutations in TGFBR1 or TGFBR2. Nat Genet 2005: 37 (3): 275-281.

76. van de Laar IM, Oldenburg RA, Pals G et al. Mutations in SMAD3 cause a syndromic form of aortic aneurysms and dissections with early-onset osteoarthritis. Nat Genet 2011: 43 (2): 121-126.

77. Boileau C, Guo DC, Hanna N et al. TGFB2 mutations cause familial thoracic aortic aneurysms and dissections associated with mild systemic features of Marfan syndrome. Nat Genet 2012: 44 (8): 916-921. DOI: 10.1038/ng.2348.

78. Lindsay ME, Schepers D, Bolar NA et al. Loss-of-function mutations in TGFB2 cause a syndromic presentation of thoracic aortic aneurysm. Nat Genet 2012: 44 (8): 922-927. DOI: 10.1038/ng.2349.

79. Maccarrick G, Black JH 3rd, Bowdin S et al. Loeys-Dietz syndrome: a primer for diagnosis and management. Genet Med 2014: 16 (8): 576-587. DOI: 10.1038/gim.2014.11.

80. Beighton P, De Paepe A, Steinmann B, Tsipouras P, Wenstrup RJ. Ehlers-Danlos syndromes: revised nosology, Villefranche, 1997. Ehlers-Danlos National Foundation (USA) and Ehlers-Danlos Support Group (UK). Am J Med Genet 1998: 77 (1): 31-37.

81. Pepin M, Schwarze U, Superti-Furga A, Byers PH. Clinical and genetic features of Ehlers-Danlos syndrome type IV, the vascular type. N Engl J Med 2000: 342 (10): 673-680.

82. Guo DC, Pannu H, Tran-Fadulu V et al. Mutations in smooth muscle alpha-actin (ACTA2) lead to thoracic aortic aneurysms and dissections. Nat Genet 2007: 39 (12): 1488-1493.

83. Zhu L, Vranckx R, Khau Van Kien P et al. Mutations in myosin heavy chain 11 cause a syndrome associating thoracic aortic aneurysm/aortic dissection and patent ductus arteriosus. Nat Genet 2006: 38 (3): $343-349$.

84. Wang L, Guo DC, Cao J et al. Mutations in myosin light chain kinase cause familial aortic dissections. Am J Hum Genet 2010: 87 (5): $701-707$.

85. Renard M, Callewaert B, Baetens M et al. Novel MYH11 and ACTA2 mutations reveal a role for enhanced TGF $\beta$ signaling in FTAAD. Int $\mathrm{J}$ Cardiol 2013: 165 (2): 314-321.

86. Braverman AC, Guven H, Beardslee MA, Makan M, Kates AM, Moon MR. The bicuspid aortic valve. Curr Probl Cardiol 2005: 30 (9): $470-522$.

87. Larson EW, Edwards WD. Risk factors for aortic dissection: a necropsy study of 161 cases. Am J Cardiol 1984: 53 (6): 849-855.

88. Laforest B, Nemer M. Genetic insights into bicuspid aortic valve formation. Cardiol Res Pract 2012: 2012: 180297. DOI: 10.1155/2012/180297.

89. Tran-Fadulu V, Pannu H, Kim DH et al. Analysis of multigenerational families with thoracic aortic aneurysms and dissections due to TGFBR1 or TGFBR2 mutations. J Med Genet 2009: 46 (9): 607-613.

90. Mizuguchi T, Collod-Beroud G, Akiyama T et al. Heterozygous TGFBR2 mutations in Marfan syndrome. Nat Genet 2004: 36 (8): $855-860$.

91. Westenskow P, Splawski I, Timothy KW, Keating MT, Sanguinetti MC. Compound mutations: a common cause of severe long-QT syndrome. Circulation 2004: 109 (15): 1834-1841. DOI: 10.1161/01.CIR.0000125524.34234.13.

92. Viswanathan PC, Benson DW, Balser JR. A common SCN5A polymorphism modulates the biophysical effects of an SCN5A mutation. J Clin Invest 2003: 111 (3): 341-346. DOI: 10.1172/JCI16879.

93. Brugada J, Blom N, Sarquella-Brugada G et al. Pharmacological and non-pharmacological therapy for arrhythmias in the pediatric population: EHRA and AEPC-Arrhythmia Working Group joint 


\section{Genetics of SCD}

consensus statement. Europace 2013: 15 (9): 1337-1382. DOI 10.1093/europace/eut082.

94. Gersh BJ, Maron BJ, Bonow RO et al. 2011 ACCF/AHA Guideline for the Diagnosis and Treatment of Hypertrophic Cardiomyopathy: a report of the American College of Cardiology Foundation/American Heart Association Task Force on Practice GuidelinesDeveloped in collaboration with the American Association for Thoracic Surgery, American Society of Echocardiography, American Society of Nuclear Cardiology, Heart Failure Society of America, Heart Rhythm Society, Society for Cardiovascular Angiography and Interventions, and Society of Thoracic Surgeons. J Am Coll Cardiol 2011: 58 (25): e212-e260. DOI: 10.1016/j.jacc.2011.06.011.

95. Fatkin D, members of the CSANZ Cardiac Genetic Diseases Council Writing Group. Guidelines for the diagnosis and management of familia dilated cardiomyopathy. Heart Lung Circ 2011: 20 (11): 691-693. DOI 10.1016/j.hlc.2011.07.008
96. Jenni R, Oechslin E, Schneider J, Attenhofer Jost C, Kaufmann PA. Echocardiographic andpathoanatomical characteristics of isolated left ventricular non-compaction: a step towards classification as a distinct cardiomyopathy. Heart 2001: 86 (6): 666-671.

97. Protonotarios N, Anastasakis A, Antoniades L et al. Arrhythmogenic right ventricular cardiomyopathy/dysplasia on the basis of the revised diagnostic criteria in affected families with desmosomal mutations. Eur Heart J 2011: 32 (9): 1097-1104. DOI: 10.1093/eurheartj/ehr043.

98. Bao J, Wang J, Yao Y et al. Correlation of ventricular arrhythmias with genotype in arrhythmogenic right ventricular cardiomyopathy. Circ Cardiovasc Genet 2013: 6 (6): 552-556. DOI: 10.1161/CIRCGENETICS.113.000122.

99. Kushwaha SS, Fallon JT, Fuster V. Restrictive cardiomyopathy. N Engl J Med 1997: 336 (4): 267-276. DOI: 10.1056/NEJM199701233360407. 